\title{
Sustainable Development and Multinational Business
}

\author{
Izdihar Baharin@ Md. Daud ${ }^{1}$, Dr. Ilham Sentosa ${ }^{2}$ \\ ${ }^{1}$ Quest International University Perak, Malaysia \\ ${ }^{2}$ City University College, Malaysia
}

\begin{abstract}
The issue of sustainability development in business had been debated at the highest level of the world governing bodies and had strong following from nations across the globe. Business today no longer sees the incorporations of sustainable development dimensions of economy, environmental, social and cultural into their business practice as additional cost structures but more as a business strategy to win over customers and markets. Since these additional costs are expensive, multinationals are the beast conduits to pursue the amalgamation of sustainable development in business.
\end{abstract}

Keywords: sustainable development, multinationals, business

\section{INTRODUCTION}

The BusinessDictionay.com [1] defined multinational business as a business entity which operates in several countries but with its headquarters in the home country and generates no less than $25 \%$ of its revenue from international operations. Multinationals is a very important source of Foreign Direct Investments (FDI's) especially for the developing world and for the developed economies, from where most of the multinational corporations (MNC's) originated, MNC's acted as a catalyst for their home and host economic growth. The World Business Council for Sustainable Development (WBSCD) in their 2005 report specifically mentioned that "by $2050,85 \%$ of world's nine billion populations will be living in the developing countries. If these people are not engaged in the marketplace, our companies cannot prosper and the benefits of a global market will not exist".

Having said that, there are no major difference between the conventional objectives of a MNC's and any other business entity, which is to maximize the value of the firm. However, more and more global corporations had accepted the hard fact that in order to sustained the progression of their own business, sustainable development principles must be incorporated into their core business practices [17]. Only then can a business both truly prosper as a viable economic entity and a responsible corporate citizen [31]

\subsection{SUSTAINABLE DEVELOPMENT}

The Brutland Report [32] defined sustainable development as "development that meets the needs of the present without compromising the ability of future generations to meet their own needs". The focus of the Butland Report can be broken into two; the first is to meet the present needs of the current generation such as economic progress, poverty eradication and social equality but at the same time, which is the second part, to ensure that the resources consumed for the benefits of current generations does not adversely affect the resources for future generation needs. In a nutshell, "we should live off the earth's interest, not its capital" [33]. It is a tough balancing act but it must be done, at the current rate " $20 \%$ of the world's population consumes $80 \%$ of its resources. If everyone consumes at this level, it wouldtake two extra planets to provide the necessary resources" [24] for mankind to prosper.

Sustainability development originates from an old German forestry term "sustainability yield". The concept, which dated back since 1713, focus on the balance between consumption and reproduction of forestry resources [13]. The concept however had already been in existence since the $12^{\text {th }}$ century [11]. In a more ancient history, the concept of sustainable development had already been in practice almost 5,000 years ago in mitigating conflicts between commercial logging activities andforest preservation in Mesopotamia[7].

\subsection{THE PILLARS OF SUSTAINABLE DEVELOPMENT}

Traditionally, there are three pillars of sustainable development; the economy, the society and the environment. In business practice, the three pillars are converted into measurable objectives which are known as the triple bottom line (TBL). Recent development however had added another dimension into the three pillars of sustainable development. The fourth pillar, which is cultural diversity, completes the framework of the triple bottom line of a business since sustainable development is ultimately about people and their values [15]. 


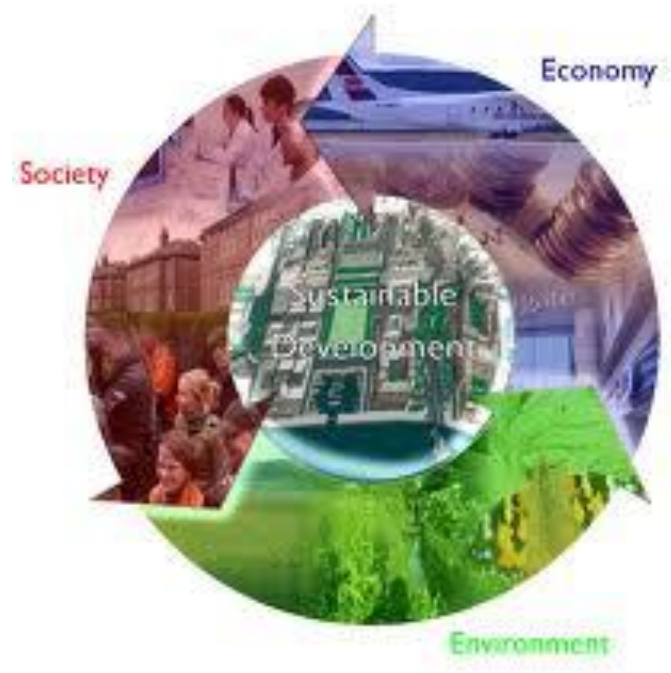

Figure 1.1: The Three Pillars of Sustainable Development

The economic pillar deals with the real existence of the business enterprise, which is to maximization of the shareholders' value. However, in the sphere of sustainable development, profits are not the only thing that should be taken into consideration in maximizing shareholders value as what is important is not a short term gain for an individual corporation anymore but comprehensive sustainable profits by the company that is able not only to sustain the business but also the industry which its operates and the economy as a whole.

The environment pillars deals specifically with the environment in which the business operates. The main focus here is not only to minimize the harmful impact of business operations to the environment but also, if possible, to restore the environment from the harm already done [33]. There had been many yardsticks developed by credible organizations to protect the environment such as the Environment, Safety \& Health [8]and Environment, Society and Governance[38] frameworks which had large support from global multinationals business such as the Shell Group and General Electric Company.

The combination of the first two pillars of sustainable development mentioned above gives birth to a terminology called the "eco-efficiency". Eco-efficiency is a concept coined by the World Business Council for Sustainable Development [30] with the objectives of producing more output from less input, hence increasing economic efficiency which using less environmental resources. This concept gained much support from the business cycles as it is very similar to the concept of productivity optimization which is a classic objective of any firm.

The social dimension or sometimes called the socio-efficiency [9] concerns with the wealth imbalance and equality between, mostly the developed and developing nations. This concept, which is surprisingly less developed compared to the environmental dimension had gained more recognition lately since business leaders are more aware that the ends of sustainable development will never be achieved without a just world society. This in our view had strongly influences the birth of the fourth dimension of sustainability development.

The cultural dimension which sometimes is synonym with cultural diversity or biodiversity [27] is the latest dimension of sustainability development and relates closely with the social dimension. Interestingly, we believed that this dimension is not only the ultimate goal of sustainable development but are also linked with the ultimate success factor in the corporate world, which is the corporate culture. We believe that the time has come that sustainable development in business operations must not only derived its strength from eco-efficiency but on a more general and global scale, focus on the social and cultural dimension of sustainable development. Once it had been accepted as part of the corporate culture, only then can sustainable development can be totally aligned with profitable business practices.

\subsection{MULTINATIONAL BUSINESS}

The importance of multinational business, both in the developed and developing world is undeniable. In 2006, 200 largest corporation accounted for more than 25\% of world Gross Domestic Product [35] and directly employed around $2 \%$ of global workforce [26]. This employment figures did not includes indirect employment which supported the multinational business in the countries they operates. The questions remain however is whether the business of multinational is actually supporting the sustainable development concept both at their origin and host countries. There had been many instances in where reputable multinational corporations were caught off-guard in unethical business practices in the areas such "sweatshops, human right violation and environmental havoc" [35]. 
As it is today, there are three main schools that dominate the discussion on multinationals. They are the anti-globalization school which decree that multinationals are bad for the economy, society and the environment. The second schools, which wholly supported the mantra espoused by Milton Friedman in 1970 that promotes "the business of doing business is business", which implies that any restrictions imposed on multinational will only hurt the activities and results of the business. The third school, which is known as the Corporate Social Responsibility (CSR) school believes that "the social responsibility of business is to increase profits" idealism will failed as not only it is ignores the social and cultural dimensions but most likely is does not conform with the values of the society at large. As such multinationals must not only seenas an agent to their shareholders, but must also be genuinely seen as a responsible corporate citizen [35].

The progression of the CSR school of thought in the operations of the multinationals, which had now morphed into sustainable development, had lent credence and legitimacy to global multinationals. Gone are the days where multinationals are depicted as global evil empires set out to ruin the government of the day or as corporations with the sole intention of maximizing profits without regards towards the environment and society. Today, multinationals businesses are seen as a major source of foreign direct investments to the developed and developing nations. Their activities had created wealth to these countries especially in terms of job creation and increase tax revenue. But what is more important today is that multinationals, mostly on voluntarily basis, had moved their focus from just being profit oriented into a more palatable objective of sustainable profits.

\subsection{TRIPLE BOTTOM LINE}

Triple Bottom Line (TBL) is a concept that measure the performance of a business from the three dimensions of sustainable development, which are corporate profits and the impact of its operations on environment and social sphere [20]. In a way, it is a method of measuring and disclosing the corporate sustainability performance of a business entity. Corporate sustainability is a concept in where business operations are built around its social and environment context. It encapsulates and extends the earlier concepts of corporate social responsibility and corporate citizenship. In a nutshell, the corporate sustainability concept goes beyond the TBL dimension. It is the whole of TBL plus the cultural diversity dimension.

TBL measures the process and report the impact of business operations on the economic, social and environmental dimension where the business operates. The focus of TBL is to provide and disclose information to all stakeholders, not just the shareholders, such as the employees, investors, government and the society at large [10]. TBL has the capacity, capability and framework to report business performance according to concerns of business sustainability [29].

\section{LITTERATURE REVIEW}

In 2006, Goldman Sachs presented three key indicators which are of main concern to the global investors and hence multinationals. They are; environment, social and government [3]. They coined the three indicators as the ESG which are closely linked to the sustainability development dimension and the TBL. Since early 2000, investors had called for greater disclosure on the impact of business operations on the ESG and corporate sustainability. Evidenced from the advanced economies had showed that there are positive linkage between good corporate citizenship and financial performance., for example, the Dow Jones Sustainability Index (DJSI) of the New York Stock Exchange (NYSE), the largest stock exchange in the world, had consistently outperform its ordinary Dow Jones Index [15].

Business stakeholders had reacted positively on the issues of sustainability development [2]. Conferences and summits such as the RIO Declaration and Agenda 21 by the United Nations (UN) had enlighten nations on the importance of sustainable development and promote the formulation and adoption of national strategies on sustainable development. One of the very important objective of the UN's Millennium Declaration is to ensure environment sustainability by aligning the sustainability development principles with national policies [16]. As more and more governments supported the UN's initiatives such as the Kyoto Protocol, this had directly set the benchmark for the nations in setting their own national guidelines for sustainable development [22].

Government plays an important role in encouraging sustainable development policies for business. A clear regulatory framework as a minimum standard on sustainable development and incentives for those who exceed the standards will augur well for the business community to integrate sustainable devolvement agendas into their standard operating procedures (SOP). This not only will allow them to stay competitive and profitable, but will also encourage them to be innovative in gaining sustainable profits. Doing the reverse will ultimately erode the competitive advantages of the multinationals in its operating business environment [12].

\subsection{MULTINATIONAL BUSINESS SUSTAINABLE DEVELOPMENT MODELS}

There are many models from where multinationals developed and implement their sustainable development practices. Below are five models which are practiced by leading multinationals with regards to sustainable development [25]. 


\subsubsection{DIVERSIFIED CONGLOMERATE MODEL}

The General Electric Company (GE) encapsulates the social, environmental and regulatory dimensions of sustainable development into its business process and evaluates its effectiveness into environmental, health and safety review, business compliance and individual key performance indicators. Communications with stakeholders are of primary concern since it providesavenues for the company to check on the consistencies between strategic planning and execution of the sustainable development policies. Three high powered committees were established to ensure compliance on the GE corporate citizenship. They are;

i. The Public Responsibility Committee (PRC) at the board level,

ii. The Citizen Executive Advisory Council (CEA) which grouped together five senior GE executives, and

iii. The Corporate Executive Council (CEC) with members includes forty of GE's top business executives. The objectives of the committees are to assess GE's performance with regards to the sustainability development issue and to gather feedback and communicate these issues to the respective stakeholders [25].

\subsubsection{THE GLOBAL MANUFACTURING MODEL}

Unilever creates two very powerful groups, the Corporate Responsibility, Issues, Sustainability and Partnership (CRISP) and the Unilever Sustainable Development Group (USDG) to guide the convergence of its business practices with sustainable development policies. Other specialized groups within Unilever sustainability framework, such as the Environment Impact Team and the Global Health Partnership Group provide support to the two main groups on sustainability issues. The responsibility of its corporate sustainability however still lies at the very top, at the shoulder of its CEO. The Unilever model put their priority on ensuring continuity and uninterrupted supplies of raw materials for its operations [25].

\subsubsection{THE GLOBALLY INTEGRATED VALUE CHAIN MODEL}

The Shell model, similar to Unilever's, rest the accountability of sustainability development issues on the shoulders of its CEO and supported by its Executive Committee members. Another high level committee, the Corporate Social Responsibility Committee (CRSC), which featured four non-executives directors, assesses Shell policies and performance with regards to its code of conduct, health, safety, security, environment and social issues and also its business practices.

Each business units are responsible in complying with the standards set upon by the CRSC and achieving the targets. Any nonconformance will be discussed at the audit committee level [25].

\subsubsection{THE FAST MOVING CONSUMER GOODS (FMCG) MODEL}

Each Global Business Units (GBU) of Proctor \& Gamble are given the responsibility of "strategic, manufacturing and sourcing" of its business activities. The GBU's however are required to integrate sustainable development issue into its business model and are accountable for its performance and reports tothe Corporate Sustainable Development Department (CSDD), which is headed "by a Director reports to the Vice President of Global Sustainability who is accountable to the President \& CEO" [25].

\subsubsection{THE TELECOMMUNICATION MODEL}

Vodafone understood that sustainability and business strategies are in congruence with each other and there are many reasons for its business to grow in line with corporate sustainability practices. In Vodafone, the sustainability issues are mitigated "through networks of issue owners" within its business operations in the local market. The CR team at the headquarters took an advisory roles in guiding its local business units in terms of sustainable development issue [25].

\subsection{SUSTAINABILITY}

Multinationals business today are facing even more delicate issues in the areas of environment, social and government, and most of them circumvent the issues by way of corporate social responsibilities [6]. Even though concerns on these issues are increasingly dominating business strategy and operations, corporate sustainability rarely became the main agenda to the business core [18].

Sustainability today is a main global agenda and a vital factor in determining the success and failures of business [5]. Sustainable development practices had created new markets, products and demand (such as in the famous case of Microsoft and Apple) and drive new business models that is heavy on innovation and light on the cost structures [18].

Corporate sustainability now is the backbone of any business and the early movers towards sustainable business practice will definitely enjoys unparalleled advantages against competitors [14]. Businesses that ignores sustainability agenda will definitely loose out in terms of profitability and market share and worse, might even risk losing monetary wealth and reputation. 


\section{Systems Modelling Approach}

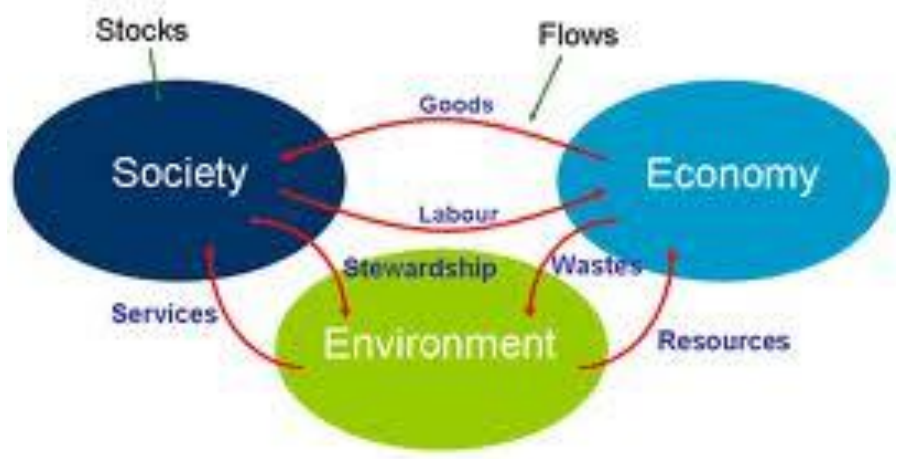

\section{Systems models track stocks \& flows over time}

Figure 2.1: The Systems Modeling Approach of Sustainable Development

\subsection{TERMINOLOGY EVOLUSION OF SUSTAINABILITY}

In line with the publication of The Brutland Report in 1987, the terminology of sustainability and sustainable development had become public mantra and issues on globalization and environment suddenly become important political agenda [4]. Since then conferences and summits such as the Earth Summit, Agenda 21 and Millennium Development Goals were held by international bodies such as the United Nations to strengthen and fortify the understanding of and importance of sustainable development among nations.

While there are many definitions on sustainable development, the most common definitions must be the one that had been put forward by the Brutland Report, which is "development that meets the needs of the present without compromising the ability of future generations to meet their own needs" [32]. Later, the term corporate sustainability was coined as a respond by the business community towards the issue of sustainable development and was derived "from other concepts of sustainable development such as the CSR and corporate accountability" [34]. This terminology had a wide following amongst sustainability movement [16] and had been strongly supported by other sustainable development definitions such as WBCSD's "simultaneous pursuits of economic prosperity, environmental equality and social equity" which propelled another widely used terminology in evaluating sustainable business performance, that is the Triple Bottom Line [21].

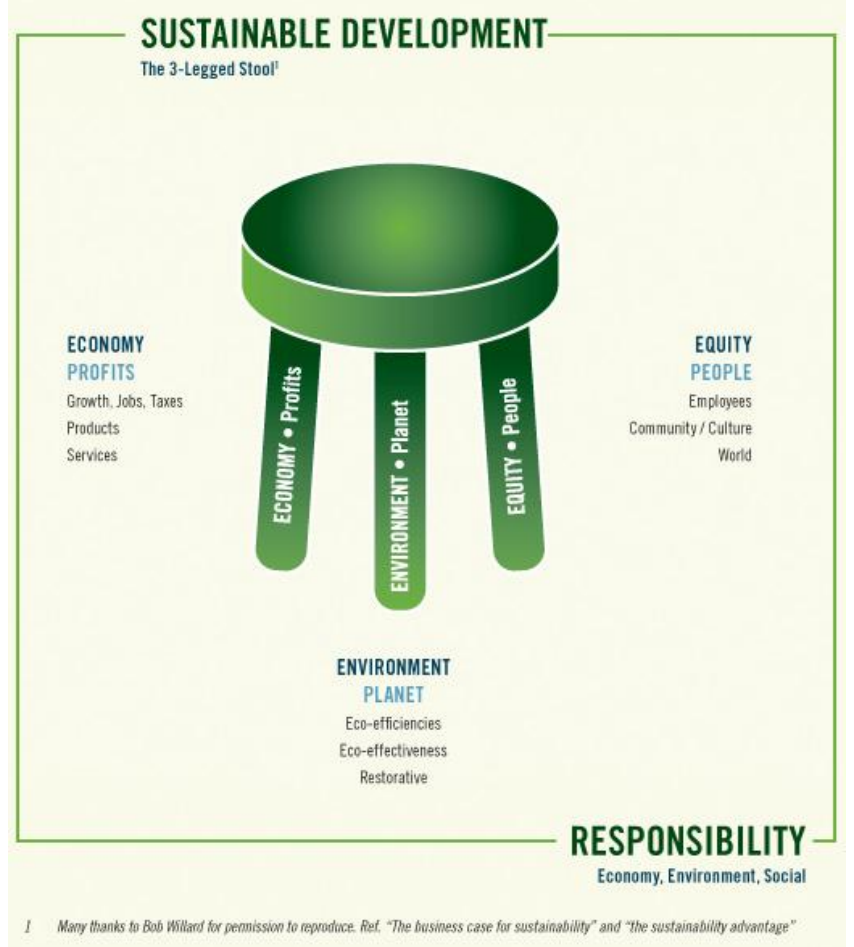

Figure 2.2: Triple Bottom Line 


\section{Sustainable Development And Multinational Business \\ III. DISCUSSION}

Multinationals (MNCs) businesses are big business. In 1997, the top 300 MNCs controlled 25\% of world's productive assets and in 1998 produced $25 \%$ of global output. By 1998 there are more than 60,000 MNCs in the world with more than 500,000 foreign affiliates. MNCs are also the main source of foreign direct investments (FDIs) both in the developed and developing world. In 1999, United States received its largest amount of FDIs ever, in the amount of USD277.5 billion. This significantly contributes towards the lowest unemployment rate in the US history of 3.9\% in the following year. Developing countries are also big beneficiaries of FDIs from the MNCs. In 1998, USD166 billion or 25.8\% of the total global FDIs in that year went to the developing countries. In terms of job creations, 86 million employees were under the employment of the MNCs in 1998. 19 million of them are in the developing world while more than 100 million more jobs was created through the multiplier effect. It was estimated by the UN that indirect jobs created by MNCs are between 3 to 7 times more than the direct jobs created. All and all, MNCs contributed significantly towards the global economy and the society at large.

Why do then multinationals businesses needs to incorporate costly sustainable development agendas into their core business strategies? There are many reasons but the main reason is always the issue of survival. In today's cut-throat competitive environment and thinning margins, the most important P's in marketing are no longer product, promotion, pricing and place, you can't really go far from you competitors since everybody are already efficient and real technological advantages are rare in today's global village. The most important P's today, which is the most important assets for any MNCs anywhere is perception! Without it the business is as good as dead.

So how does perception relates to sustainable development? Remember the $3+1$ dimensions of sustainable development; profits, environment, social and cultural diversity (or profits, people and planet). All these dimensions have one very important input in common, that is the human element. In the world of free information flow, equal access to education and knowledge based economy, it is the people that create products and markets, it is the people that runs businesses and it is them who is living and will inherited this planet.

There is a very strong bond between sustainable development and good business. A good business strategy will always be thinking of ensuring sustainable growth and profits endlessly. The going concern principle dictates this. As such it is always good business sense to ensure that they are operating in a way that not only will minimize the harmful impact on the environment but also when possible to reverse the harmful affect that had already been done to the planet. Many MNCs today is already at the forefront of the "green revolution" and found that not only these new businesses is helping them to elevate their reputation higher but also contributing immensely to their bottom line.

On a more "difficult" note, MNCs had ventured into more "gray" areas of social and cultural dimensions of sustainable development. More and more companies, such as in the apparel industries, had abandoned their sweatshops in the third world countries for a more socially just arrangements. In the cultural dimension, the "one size fits all" concepts which were one the dominant culture of MNCs had been slowly change to accept diversity as part of their business model. In congruence with the environmental dimension, MNCs today are more willing to spend more on the social and cultural dimension not only to maintain and increase their "perception profile" but also, most importantly, to avoid any negative repercussions from their customers and other stakeholders.

In a nutshell, aligning sustainable development with good business practices is costly but unavoidable. The cost of doing sustainability business in ensuring the overall good of the planet is enormous yet supremely profitable but at the current rate, is prohibitive to the small, medium and even large scale local industries. As such it is the duty of MNCs to show the way that business and sustainable development are just good business sense.

\section{CONCLUSION}

Sustainable business is not a new concept. It had existed for nearly 5,000 years ago in the ancient Mesopotamian kingdom and had evolved ever since. The impetus of sustainable development started somewhere in the 70's under the disguised of corporate social responsibility (CSR), then later corporate responsibility (CR) and at present under a new name of corporate sustainability (CS). This paper intentionally left the review of literatures and discussion on CSR, CR and CS due to its main focus on sustainable development and its dimensions.

Sustainable development is a good business. MNCs in the advanced countries which incorporated their business strategies with the sustainable development dimension had consistently outperformed their competitors that neglect the elements of sustainable development. Companies such as Novo Nordisk, ABB, Wal Mart and many more had successfully integrated sustainable development into their business practices which not only yielded better economic returns but also positive contributions towards their operating environment, social sphere and cultural diversity. Even though currently the "social and cultural management tools are less developed than environmental management tools" (James 2000) more than 1,100 MNCs had opted to use the General Reporting Initiatives (GRI) framework for their sustainability reporting in 2009 [23]. 
Incorporating sustainable development dimensions into business practices is difficult since it is mostly seen as an additional cost to the business. Most businesses in the developing countries just do not have the financial resources and technical capabilities to practice corporate sustainability even do they want to. Furthermore the framework at the national levels of the developing countries might not be attractive enough for them to promote sustainability business. As such it is a civic duty for the MNCs, which have enormous resources and influence to promote corporate sustainability especially when operating in the developing world. Who knows, they might be able to start a sustainable development revolution there!

\section{ACKNOWLEDGEMENT}

The writer would like to acknowledge the immense contribution and guidance given by Prof. Dr. A. Selvanathanof City University College, Malaysia in completing this paper. The author would also like to acknowledge the support of Scholl of Business, University of Ballarat, Australia in doing the same.

\section{REFRENCES}

[1] www.businessdictionary.com

[2] Adams, W. M. a. J., S.J., Transition to Sustainability: Towards a Humane and Diverse World Switzerland,(IUCN, 2008)

[3] Shareholder Value Workshop - Integrating ESG into Investment Research,(Global Investment Research, 2006).

[4] Bello, W.,Time to Lead. Time to Challenge WTO. Focus on Trade,(UNCTAD, 2000).

[5] Bonini, S., Koller, T.M., Mirvis, P.H., Valuing Social Responsibility,McKinskey Quaterly,2009, 11-18.

[6] Carroll, A. B., Corporate Social Responsibility: Evolution of A Defitional Construct,Business \& Society, (38), 1998, $268-295$.

[7] CCM,Driving Business and Beyond Profitability. Corporate Resposibility Agenda,(Companies Commison of Malaysia, 2009).

[8] Carbon Disclosure Project, (CDP, 2008).

[9] Dylick, T., and Hockets, K.,Beyond the Business Case for Corporate Sustainability,Business Strategy and the Environment 11(2), 2002, 130-141.

[10] Elkington, J.,Cannibals with Forks: The Tripple Bottom Line of 21st Century Business, (New Society Publisher, 1997).

[11] Enhert, I.,Sustainable Human Resources Management: A Conceptual and Exploratory Analysis from a Paradox Perspective, (Springer, 2009).

[12] Esty, D. C. a. W., A.S,Green to Gold,(New Haven, CT, Yale University Press, 2006).

[13] Finn, D.,Our Uncertain Future: Can Good Planning Create Sustainable Communities?,(University of Illinois, 2009)

[14] Holme, R., Watts, P.,Making Good Business Sense,(WBCSD, 2000).

[15] James, P.,Business, Eco-Efficiency and Sustainable Development,(University of Bradford, 2000).

[16] Katsaulakos, T. a. K., Y., Integrating Corporate Responsibility Principles and Stakeholders Approaches into Mainstream Strategies: A stakeholder orinted and integrative strategic management framework,Corporate Governance(7), 2007, $355-369$.

[17] Krehmeyer, D., Lenox, M., \& Moriarty, B., Sustainability Strategy As Corporate Strategy, (http://ethicsphere.com/sustainabilitystrategy-as-a-corporate-strategy)

[18] Lacy, P., Berthon, B., Teo, L.L., Boer, Y.D.,A New Era of Sustainability: Perspectives from Asia Pacific CEO's,(United Nation Global Compact \& Accenture, 2010).

[19] Lacy, P., Cooper, T., Hayward, R., Nueberger, L.,A New Era of Sustainability. New York,(United nation Global Compact \& Accenture, 2010).

[20] Macdonal, M. a. P., K.A.,Review of Corporate Sustainability Reporting, (Sustainability Reporting Programme, 2003)

[21] Marshall, R. S., Harry, S.P.,Introducing A New Business Course: Global Business and Sustainability,International Business of Sustainability in Higher Education, (6), 2005, 171-179.

[22] Mazurkiewicz, P.,Corporate Environmental Responsibility: Is a common CSR framework possible?,(World Bank, 2004).

[23] Moffat, A.,The 21st Century Corporation: The Ceres Roadmap For Sustainability,(Coalition for Environmentally Responsible Economies (CARES), 2010).

[24] Porritt, J.,The Role of Business in Society: Delivering Sustainable Developement, (PwC Partner Conference, 2006)

[25] Selvanathan, P. J.,Identifying The Key Determinants of Effective Corporate Sustainability Reporting by Malaysian GLCs, doctoral diss., Southern Cross University, Australia, 2011.

World Investment Report, (UNCTAD, 2006).

[27] The Universal Decleration on Cultural Diversity, (UNESCO, 2001).

[28] United Nation Global Compact Report, (UNGC, 2009).

[29] Vanclay, F., The Tripple Bottom Line and Impact Assessment: How do TBL, EIA, SIA, SEA and EMS relates to each other?,Journal of Environmental Assessment Policy and Management, 6, 2004, 265-288.

[30] Changing Courses, (WBCSD, 1992)

[31] World Business Council for Sustainable Development Report, (WBCSD, 2005).

[32] World Commission on Environment and Development Report, (WCED, 1987).

[33] Willard, B.,The Sustainability Advantage,(British Columbia, 2002)

[34] Wilson, M., Corporate Sustainability: What is it and where does it come from?,Ivey Business Journal, (March/April), 2003, 1-5.

[35] Witte, T. B. a. J. M., Rules for Global Players? Governing Multinationals Corporations in Developing Countries,IP, 2006, Fall. 